\title{
Xist-deficient mice are defective in dosage compensation but not spermatogenesis
}

\author{
York Marahrens, ${ }^{1}$ Barbara Panning, ${ }^{1}$ Jessica Dausman, ${ }^{1}$ William Strauss, ${ }^{2}$ and Rudolf Jaenisch ${ }^{1,3,4}$ \\ ${ }^{1}$ Whitehead Institute for Biomedical Research, Cambridge, Massachusetts 02142 USA; ${ }^{2}$ Department of Medicine, Beth Israel \\ Hospital, Harvard Medical School, Boston, Massachusetts 02215 USA; ${ }^{3}$ Massachusetts Institute of Technology, \\ Cambridge, Massachusetts 02142 USA
}

\begin{abstract}
The X-linked Xist gene encodes a large untranslated RNA that has been implicated in mammalian dosage compensation and in spermatogenesis. To investigate the function of the Xist gene product, we have generated male and female mice that carry a deletion in the structural gene but maintain a functional Xist promoter. Mutant males were healthy and fertile. Females that inherited the mutation from their mothers were also normal and had the wild-type paternal $X$ chromosome inactive in every cell. In contrast to maternal transmission, females that carry the mutation on the paternal $\mathrm{X}$ chromosome were severely growth-retarded and died early in embryogenesis. The wild-type maternal $X$ chromosome was inactive in every cell of the growth-retarded embryo proper, whereas both $X$ chromosomes were expressed in the mutant female trophoblast where $X$ inactivation is imprinted. However, an XO mouse with a paternally inherited Xist mutation was healthy and appeared normal. The imprinted lethal phenotype of the mutant females is therefore due to the inability of extraembryonic tissue with two active $X$ chromosomes to sustain the embryo. Our results indicate that the Xist RNA is required for female dosage compensation but plays no role in spermatogenesis.
\end{abstract}

[Key Words: Xist gene; mice; dosage compensation; spermatogenesis; $\mathrm{X}$ inactivation]

Received October 29, 1996; revised version accepted December 6, 1996.

Early in mammalian embryogenesis, an unidentified signal causes one of the two X chromosomes of female cells to assume properties of heterochromatin, a process called $\mathrm{X}$ inactivation. The inactive $\mathrm{X}$ chromosome is visibly condensed during interphase (Barr 1959; Ohno and Hauschka 1960), late replicating (Lyon 1972), hypoacetylated (Jeppesen and Turner 1993), and transcriptionally repressed (Lyon 1961; Russell 1961; Beutler et al. 1962). Once established, the heterochromatin structure is stably inherited in the somatic lineages of the organism. X inactivation ensures that females with two $\mathrm{X}$ chromosomes express $\mathrm{X}$-linked genes at the same level as males that have only one.

Studies of $\mathrm{X}$-autosome translocations led to the discovery of a region called the $X$ inactivation center (Xic) that must be present in cis for chromosomal inactivation to occur (Russell 1963; for review, see Rastan and Brown 1990). Interestingly, linked autosomal genes on X-autosome translocation products are sometimes also inactivated (for review, see Eicher 1970). The pattern of inactivation of linked autosomal sequences indicates that heterochromatin can spread from the X chromosomal

${ }^{4}$ Corresponding author.

E-MAIL Jaenisch@WI.MIT.edu; FAX (619) 258-6505. sequences into the autosomal region (Eicher 1970). A 450 -kb yeast artificial chromosome (YAC)-derived transgene has been shown recently to exhibit properties of the Xic (Lee et al. 1996), opening the door to studies at higher resolution.

The Xist gene resides within the Xic and encodes an untranslated RNA that is expressed exclusively from the inactive X chromosome (Borsani et al. 1991; Brockdorff et al. 1991, 1992; Brown et al. 1991, 1992). Recently, Xist has been shown to be required in cis for $\mathrm{X}$ inactivation using a targeted mutation in female embryonic stem (ES) cells (Penny et al. 1996). This raises two possibilities regarding the role of Xist in $\mathrm{X}$ inactivation. The first possibility is that the Xist promoter, but not the RNA gene product, is required to silence other genes in cis, as has been hypothesized for another RNA gene, H19 (Zemel et al. 1992; Pfeifer and Tilghman 1994; Leighton et al. 1995). Alternatively, the Xist gene product is required for inactivation. A role of the Xist RNA in heterochromatin formation is strongly suggested by fluorescence in situ hybridization (FISH) studies that indicate that the $X$ ist RNA coats the inactive chromosome (Brown et al. 1992; Clemson et al. 1996; Panning and Jaenisch 1996).

Two types of $\mathrm{X}$ inactivation patterns are seen in female tissues. In all cells of marsupials and in extraem- 
bryonic tissues of rodents, $\mathrm{X}$ inactivation is imprinted as only the $\mathrm{X}$ chromosome inherited from the father is inactivated (Takagi and Sasaki 1975). In somatic cells of most mammals, on the other hand, either the paternal or the maternal $\mathrm{X}$ chromosome may be inactivated in a given cell. $\mathrm{X}$ inactivation in the epiblast is therefore said to be random. It has been proposed that one $\mathrm{X}$ chromosome is rendered nonresponsive to the inactivation signal (Rastan 1983). Interestingly, Xist is inappropriately expressed in male methyltransferase-deficient embryos leading to $\mathrm{X}$ inactivation in, at least, a subset of cells in the embryo (Beard et al. 1995; Panning and Jaenisch 1996). Methylation may therefore be required to shield one $\mathrm{X}$ chromosome from the inactivation signal in both imprinted and randomly inactivating cells. Methylation appears to have a similar role in the maintenance of the autosomal H19 imprint; H19 is expressed from the normally inactive allele in methyltransferase-deficient embryos (Li et al. 1993).

$\mathrm{X}$ inactivation also occurs during spermatogenesis. The $\mathrm{X}$ chromosome becomes condensed early in prophase of meiosis I, first associating with the Y chromosome, a structure called the sex body, and then becoming a distinct entity as prophase progresses. The $\mathrm{X}$ chromosome is transcriptionally repressed throughout prophase, whereas the autosomes are actively transcribed much of the time (Henderson 1965; Monesi 1965). Interestingly, in males, Xist is transcribed only in the testes (Borsani et al. 1991; McCarrey and Dilworth 1992; Richler et al. 1992; Salido et al. 1992). It is not known, however, whether $\mathrm{X}$ inactivation in spermatogenesis and in female somatic cells is accomplished by similar mechanisms.

To study the biological role of the Xist gene product, male and female mice carrying a targeted deletion of the $X i s t$ gene were generated. Spermatogenesis was normal in Xist-deficient males indicating that $\mathrm{X}$ inactivation in males and females occurs through distinct mechanisms. The mutation caused female lethality dependent on its parental origin: Females carrying a maternally transmitted Xist deletion were viable, whereas paternal transmission of the mutation resulted in embryonic lethality as a result of malfunctioning extraembryonic tissue.

\section{Results}

\section{Males with a Xist deletion are fully fertile}

To determine the role of Xist RNA in X inactivation and imprinting, a targeting construct was designed to replace $\sim 15 \mathrm{~kb}$ of the Xist gene with the neomycin resistance gene, leaving the promoter intact (Fig. 1A). The targeting construct was introduced into J1 cells, a male ES cell line generated from 129 mice. Thirty-eight neomycin-resistant colonies were assayed by DNA blot hybridization, and one was determined to carry a correctly targeted mutation at the Xist locus (Fig. 1B; data not shown). Xist is transcribed at low levels in ES cells and is readily detected at the Xist locus by FISH (Lee et al. 1996; Panning and Jaenisch 1996). To determine whether the mutant allele was transcribed, RNA FISH was performed on
Xist-deficient ES cells and $\mathrm{Jl}$ cells using a probe that recognizes the $5^{\prime}$-undeleted region (Fig. 5A, below). Identical RNA expression patterns were seen in wild-type (Fig. 5B, below) and mutant ES cells (Fig. 5C, below) indicating that the deletion did not disturb Xist transcription (Panning and Jaenisch 1996).

Xist-deficient ES cells were used to generate 17 chimeras that were identified by the presence of agouti coat color and black eyes produced by the targeted 129 cells against an albino host background. Thirteen of the chimeras were males with up to $95 \%$ of coat color derived from mutant cells. As all chimeras appeared normal, Xist-deficient male cells appeared to contribute normally to somatic tissues.

To determine whether Xist-deficient cells can undergo spermatogenesis, we crossed male chimeras to female albino mice. Of the 13 males, 11 sired pups with dark fur demonstrating that Xist-deficient cells can undergo spermatogenesis. Three of these male chimeras exclusively sired pups with dark fur. The three chimeras were fully fertile indicating that spermatogenesis was not impaired. The pups descended from cultured ES cells appeared normal and healthy. Significantly, all of the pups were male (Table 1) with one exception: a female that was determined to be XO (see below). Because only females would inherit the mutant $\mathrm{X}$ chromosome, the observation that only males are born raised the possibility that the Xist mutation prevented formation of mutant (X-containing) sperm but not of wild-type (Y-containing) sperm. Alternatively, sperm carrying the mutant Xist allele were unable to fertilize eggs. A third possibility was that female mice heterozygous for the mutation died during embryogenesis.

To investigate whether functional Xist-deficient sperm were produced, day 3.5 embryos sired by male chimeras were recovered and the presence of mutant female embryos tested by assaying for the presence of the neomycin resistance gene using PCR. The neomycin resistance gene was detected in DNA obtained from pools of day 3.5 embryos sired by male chimeras but not from embryos sired by BALB/c males (Fig. 1C). We conclude that the Xist gene is not required for sperm formation or function and that females heterozygous for the Xist defect die during embryogenesis.

\section{Female embryonic lethality}

The observations described above indicated that females inheriting the Xist mutation die after cleavage. To characterize the mutant phenotype, conceptuses sired by male chimeras were recovered at different stages of gestation and photographed. Mutant embryos were initially identified by PCR amplification of a portion of the neomycin resistance gene. To exclude misidentification of embryos as a result of DNA contamination, several embryos were subjected to two additional PCR assays that would distinguish female mutant from wild-type embryos. PCR amplification of the $Z$ fy gene, which is exclusively located on the $\mathrm{Y}$ chromosome, was used to determine the sex of the embryo. Amplification of a por- 
Figure 1. Targeted mutagenesis of the $X$ ist gene in mouse ES cells and generation of mutant mice. (A) Map of the genomic region containing the mouse Xist gene (top) and the targeting replacement vector used for electroporation (middle). In the mutant locus (bottom), $\sim 15 \mathrm{~kb}$ of genomic sequence has been replaced with a neo expression cassette. Exons are represented as black boxes and are numbered. (B) DNA blot of wild-type and mutant ES cell clones. After NcoI digestion of genomic DNA, a $16.7-$ or an $8.2-\mathrm{kb}$ band is detected from the wild-type or targeted allele, respectively, through the use of a probe that recognizes the $3^{\prime}$ end of the gene. (C) PCR amplification from genomic DNA isolated from pools of E3.5 embryos was performed using primers that amplify a 477-bp fragment of the neo gene. PCR products were electrophoresed on an acrylamide gel with bacteriophage $\lambda$ DNA digested with the restriction enzyme BstEII as a size marker (left). Source of genomic DNA template is indicated above each lane of the gel. Neo+

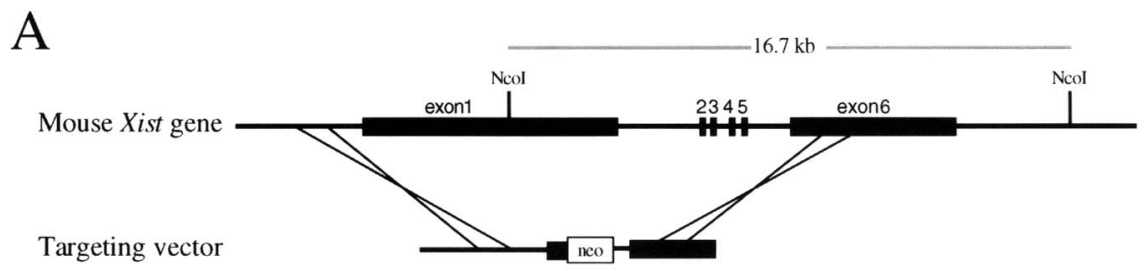
and $\mathrm{NeO+}(1 / 10)$ are template DNAs obtained from matings of wild-type females to males heterozygous for a neo expression cassette at the integrin $\alpha 1$ locus (Gardner et al. 1996). Exptl and Neo- are from matings of wild-type females to male Xist-deficient chimeras and wild-type males, respectively. (No DNA) No template DNA. (D) PCR amplification from genomic DNA isolated from E8.5 littermates. DNA samples were amplified by PCR using primers that recognize the neo (top), $Z f_{y}$ (middle), and Igf2 (bottom) genes. Products were electrophoresed on agarose (top, middle) or sequencing (bottom) gels. Radioactive amplification products from the Igf2 gene were visualized using autoradiographic film. Polymorphisms in the Igf2 sequence cause amplification products from 129 DNA to migrate more rapidly than the amplification products from host (BALB/c) DNA. (Lane 1) E8.5 129/BALB/c (mutant) female; (lane 2) 129/129 adult male; (lane 3) E8.5 BALB/c/ $\mathrm{BALB} / \mathrm{c}$ female; (lane 4) J1 ES cells; (lane 5) targeted 11 ES cells; (lane 6) E8.5 129/BALB/c male. The E8.5 embryos were littermates.

tion of the Igf2 gene that includes a strain-specific polymorphism was used to identify embryos descended from the Xist-targeted cells. The three PCR assays were in full agreement with one another and independently identified 18 wild-type embryos and 2 mutants among 20 conceptuses tested (Fig. 1D).

Visual inspection of mutant conceptuses identified by PCR revealed a severe growth defect that manifested itself early in embryogenesis. At embryonic day 6.5 (E6.5), mutant conceptuses were slightly smaller than wildtype littermates (Fig. 2A). Growth was severely reduced

Table 1. Pups born to Xist-deficient male chimeras

\begin{tabular}{|c|c|c|c|}
\hline \multicolumn{4}{|c|}{ Offspring (no. of pups) derived from } \\
\hline \multicolumn{2}{|c|}{ host } & \multicolumn{2}{|c|}{ targeted ES cells } \\
\hline male & female & male & female \\
\hline 75 & 97 & 145 & $1^{\mathrm{a}}$ \\
\hline \multicolumn{4}{|c|}{$\begin{array}{l}\text { Xist-deficient male chimeras were mated to BALB/c females } \\
\text { and the gender of } 172 \text { albino pups descended from the host, and } \\
146 \text { pups with agouti coat color and brown eyes (descended from } \\
\text { targeted ES cells) was determined. } \\
\text { aThe one female pup born to a male chimera was determined to } \\
\text { be XO and did not carry the Xist mutation. }\end{array}$} \\
\hline
\end{tabular}

between E6.5 and E10.5 (Fig. 2A,B). Most E10.5 mutants showed signs of degradation (not shown). At E12.5, mutant conceptuses were being reabsorbed and could not be recovered.

To characterize the mutant phenotype in more detail, a large number of E8.5 conceptuses were isolated from decidua, photographed, and then genotyped by PCR (Fig. 2). In addition, a second set of conceptuses was sectioned and examined by histological analysis. To identify cells of the trophectoderm and primitive endoderm extraembryonic lineages where $\mathrm{X}$ inactivation is imprinted, we stained sections with an antibody to Pem (Fig. 3), a homeo-box-containing protein that is specifically expressed in the extraembryonic lineage (Lin et al. 1994). Of 72 dissected embryos that were descended from the mutant ES cells, 32 were mutant females. The mutant E8.5 conceptuses were approximately the size of wildtype E6.5 conceptuses (Fig. 2A,D-F) with the yolk sac being either expanded (Figs. $2 \mathrm{D}$ and $3 \mathrm{~B}$ ) or, more frequently, tightly adhering to the embryonic component (Figs. 2E,F, and 3C,D). The imprinted component of the yolk sac in wild-type conceptuses consists of giant cells and visceral and parietal endoderm (Fig. 3E). Giant cells were present in the mutant yolk sac, but were smaller, not well formed, and greatly reduced in number (Fig. 3F). Visceral and/or parietal endoderm were also present but 

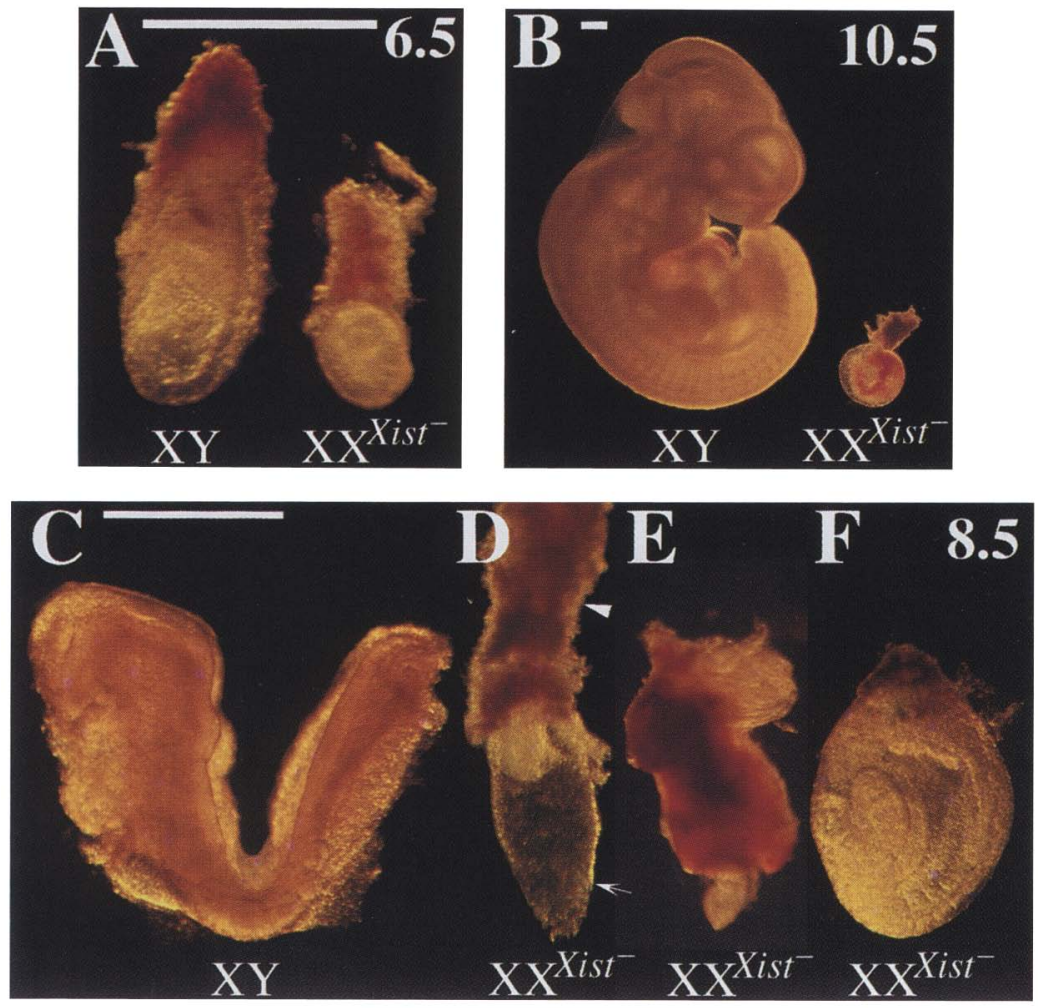

Figure 2. Phenotypic comparison of wild-type and mutant littermates at $6.5,8.5$, and 10.5 days of gestation. Bar scale, $0.5 \mathrm{~mm}$. (A) Whole view of an E6.5 wild-type conceptus (left) and a mutant littermate; $(B)$ whole view of an E10.5 wild-type embryo (left) and a mutant embryo with yolk sac and trophoblast; $(C)$ side view of E8.5 wild-type embryo; $(D-F)$ view of mutant E8.5 conceptuses. (Arrowhead) Ectoplacental cone; (arrow) yolk sac. could not be distinguished as both tissues express the Pem protein. Visceral mesoderm, the nonimprinted component of the yolk sac that does not express Pem, was also present (Fig. 3F). Mutant E8.5 ectoplacental cones were usually small, although sometimes quite elongated (Fig. 2D), but variable in size and contained some giant cells as well as maternal cells (Fig. 3G). Maternal cells in the ectoplacental cone were identified by lack of immunostaining for the Pem protein.

Development of the embryonic component was highly variable. Some conceptuses had almost no embryonic component $(2 / 32$, not shown) or a small epithelium-like component $(4 / 32$; Figs. $2 \mathrm{D}$ and $3 \mathrm{~B})$ and appeared not to have undergone gastrulation. In other conceptuses the embryonic component occupied a larger subset or all of the yolk sac (26/32; Figs. 2E,F and 3C,D). Most embryos were very disorganized (see Figs. $2 \mathrm{E}$ and $3 \mathrm{C}$ for examples) making it difficult to identify tissues without testing for multiple lineage-specific markers. Conceptuses with disorganized or partially disorganized embryonic components were often covered in blood (Fig. 2E) and frequently included a balloon-like structure protruding from the caudal end of the embryo, probably the allantois (Fig. 2E) (Spindle et al. 1996). A subset of the E8.5 mutant embryos had developed further, and specific tissues and structures could be identified. The best developed mutants displayed a recognizable body plan corresponding to wild-type E8.5 embryo and contained amnion, neural folds, posterior and anterior neural groove, somites, and allantois (3/32, Figs. $2 \mathrm{~F}$ and $3 \mathrm{D})$.
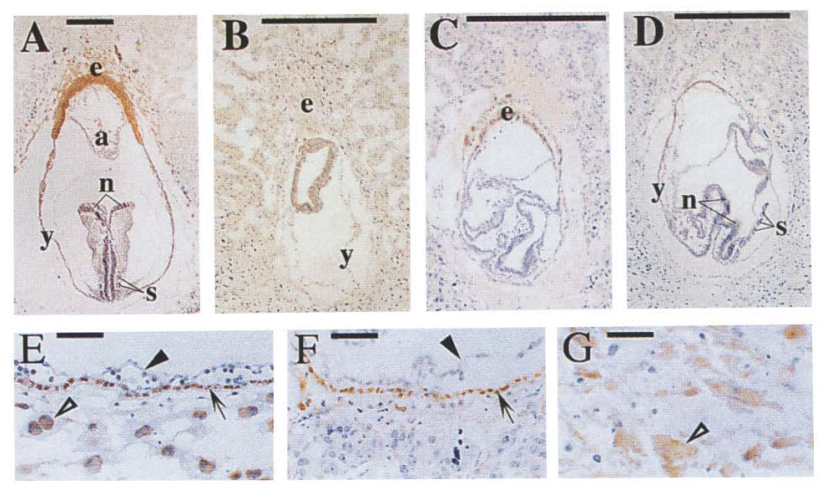

Figure 3. Immunostaining of Pem protein in E8.5 conceptuses. Sections are of embryos in situ. All sections were immunostained for Pem protein (brown) and counterstained with hematoxylin (blue). Pem is expressed only in the extraembryonic trophectoderm and primitive endoderm lineages where $\mathrm{X}$ inactivation is imprinted. (Y) Yolk sac; (arrowheads) visceral mesoderm of yolk sac; (arrows) visceral and/or parietal endoderm of yolk sac; (open arrowheads) giant cells; (n) neural folds; (e) ectoplacental cone; (a) allantois; (s) somites. Bar scale, $0.5 \mathrm{~mm}$ unless otherwise noted. (A) Transverse section of wild-type E8.5 embryo showing neural folds; $(B)$ mutant E8.5 embryo that has failed to undergo gastrulation and has an elongated ectoplacental cone; $\{C \mid$ partially disorganized mutant embryo; $(D)$ mutant embryo with neural groove and somites; $(E)$ yolk sac of wildtype conceptus (bar, $50 \mu \mathrm{m}) ;(F)$ yolk sac of mutant conceptus (note the severely reduced number of giant cells; bar, $50 \mu \mathrm{m}$ ); $(G)$ mutant ectoplacental containing unstained maternal cells (bar, $20 \mu \mathrm{m})$. 


\section{Xist required for imprinted $X$ inactivation}

To determine whether the Xist-deficient $\mathrm{X}$ chromosome is inactivated, gene expression from wild-type and $\mathrm{mu}$ tant paternal X chromosomes in the extraembryonic cells of ectoplacental cones was compared by assaying the enzyme activity levels of the X-linked hypoxanthine phosphoribosyl transferase (Hprt) gene (Monk 1987). The Hprt assay was selected because it is quantitative and can be performed on small samples (Monk 1987). The Hprt enzyme activity level of Xist-deficient ectoplacental cones was nearly twice that of wild-type ectoplacental cones (Fig. 4A). Because the mutant ectoplacental cones are primarily composed of extraembryonic cells (Fig. 3G), we conclude that there is approximately a twofold increase in X-linked Hprt gene expression in mutant extraembryonic cells, suggesting that both Hprt alleles were expressed.

In wild-type trophoblast, the maternal $\mathrm{X}$ chromosome is active and the paternal $\mathrm{X}$ chromosome is transcriptionally silent. To verify that elevated Hprt expression in mutant tissue was attributable to Hprt expressed from the normally inactive paternal allele, male chimeras and control males were mated with females homozygous for a null mutation at the Hprt locus (Hooper et al. 1987). Hprt activity recovered from conceptuses produced by these matings should be attributable entirely to expression from the paternal $\left(\mathrm{Hprt}^{+}\right) \mathrm{X}$ chromosome, as the maternal X chromosome in the mutant cells is $\mathrm{Hprt}^{-}$. In addition, any maternal cells included in the sample would be $\mathrm{Hprt}^{-} / \mathrm{Hprt}^{-}$. The Hprt enzyme activity level produced by an active paternal $\mathrm{X}$ chromosome was ex-
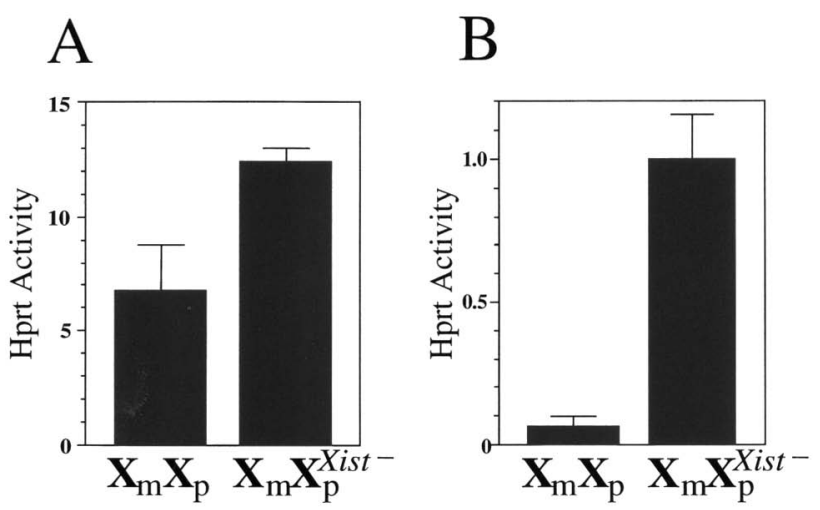

Figure 4. The Hprt gene is expressed from both $\mathrm{X}$ chromosomes in Xist-deficient trophoblast. Enzyme activity levels were determined simultaneously from trophoblast extracts for the X-linked Hprt and autosomal Aprt genes (Monk 1987). Values obtained from the Aprt enzyme assay were used to normalize the Hprt enzyme activity levels. (A) Hprt activities in E7.5 wild-type and E8.5 mutant trophoblast. E7.5 trophoblast was used because it most closely resembles the E8.5 mutant trophoblast in development. Averages and standard deviations of seven wild-type and three mutant samples are shown. $\{B\rangle$ Hprt activities in E7.5 wild-type and E8.5 mutant trophoblast obtained from pregnant $\mathrm{Hprt}^{-} / \mathrm{Hprt}^{-}$females. Averages and standard deviations of three wild-type and three mutant samples are shown. pected to be lower in this experiment than in Figure 4A because the $\mathrm{Hprt}^{-1-}$ strain has been shown to introduce a genetic background that substantially reduces the Hprt activity levels in certain heterozygous strains (Moore and Whittingham 1992). As expected, very little Hprt activity was recovered from ectoplacental cones with a wild-type paternal $\mathrm{X}$ chromosome, indicating that the chromosome was inactive (Fig. 4B). Hprt enzyme activity levels recovered from Xist-deficient ectoplacental cones were 16-fold higher than the activity of the wildtype tissue (Fig. 4B) indicating that the paternal $\mathrm{X}$ chromosome was active in Xist-deficient tissue.

FISH was used to examine the $\mathrm{X}$ inactivation pattern in Xist-deficient embryos. Because Xist RNA is expressed at high levels exclusively from the inactive $X$ chromosome and coats the chromosome from which it is expressed, it was used as a molecular marker for the inactive X chromosome. Pgk-1 RNA, on the other hand, can be identified at a transcriptionally active $P g k-1$ locus using FISH (Panning and Jaenisch 1996) and was therefore used as a molecular marker for the active $\mathrm{X}$ chromosome. Therefore, these two signals unambiguously distinguish the inactive and active $\mathrm{X}$ chromosomes. For this analysis we selected advanced mutant embryos with neural folds similar to the embryo shown in Figure 2F. The neural folds of the embryos were dissected, partially dissociated, and fixed on coverslips. The remaining portion of the conceptuses was used to genotype the embryos by PCR (not shown). RNA FISH was performed on preparations of mutant and wild-type female embryonic cells using a probe that recognizes exon 1 sequence deleted in the Xist mutant ( $3^{\prime}$ probe, Fig. 5A). This probe, therefore, specifically recognizes Xist RNA from the intact maternal allele. The cells were simultaneously assayed with a probe that recognizes $P g k-1$ transcripts (wild-type female, Fig. 5D). As expected, no Xist expression was seen in male cells (Fig. 5E). In all mutant cells examined, Xist was expressed from the maternal X chromosome and $P g k-1$ was expressed only from the mutant $\mathrm{X}$ chromosome (Fig. $5 \mathrm{~F}$ ) indicating that the mutant $\mathrm{X}$ chromosome was active and the maternal $\mathrm{X}$ inactive in all cells.

The observation that the Pgk-1 gene was expressed only from the mutant $\mathrm{X}$ chromosome in mutant embryos indicates that in contrast to extraembryonic cells, mutant embryos were genetically balanced with one active $\mathrm{X}$ chromosome. To confirm this observation, the neural folds of E8.5 wild-type embryos and the best developed E8.5 mutant embryos were dissected and subjected to the Hprt assay. The remaining portion of the embryos was used to determine the genotype of the samples by PCR. Hprt enzyme activity levels were nearly identical in wild-type and Xist-deficient female embryos (not shown). Therefore, two lines of evidence indicate that the Xist-deficient embryos are genetically balanced.

\section{Females with a maternally inherited Xist mutation and mutant males are normal}

The observations that only one $\mathrm{X}$ chromosome was ac- 
A
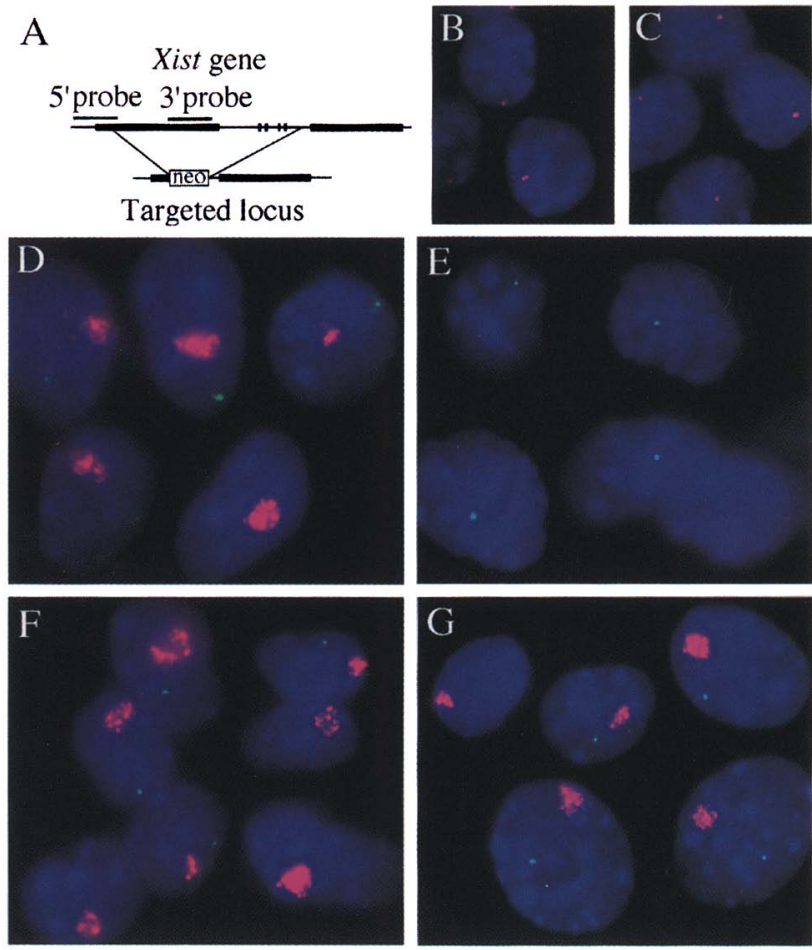

Figure 5. Xist expression in wild-type and mutant cells. FISH for Xist (pink/red) and $P g k-1$ (green) RNAs in cells from undifferentiated ES cells $(B, C)$, E8.5 epiblast $(D-F)$, and fibroblasts of a 2-week-old pup $(G)$. (A) Map of the Xist locus and position of the probes used. The $5^{\prime} X$ ist probe was used in $B$ and $C$; the $3^{\prime}$ probe, which recognizes only the wild-type locus, was used in $D-G$. $(B)$ Wild-type male; $(C)$ mutant male; $(D)$ wild-type female; $(E)$ wild-type male; $(F)$ female with a paternally inherited Xist mutation; $(G)$ female with a maternally inherited Xist mutation.

tive in each cell of the mutant embryo proper, whereas both $\mathrm{X}$ chromosomes were expressed in the imprinted extraembryonic tissues raised the possibility that the lethality was entirely attributable to the malfunction of the extraembryonic tissue. If this was the case, then females carrying the Xist mutation on the maternal X chromosome should be normal, as Xist is not expressed from the maternal $\mathrm{X}$ chromosome in the extraembryonic tissues. To determine the role of the imprinted mutant extraembryonic tissues in the lethal phenotype we attempted to obtain mice that had inherited the mutation from their mothers. E2.5 embryos, obtained from the mating of Xist-deficient male chimeras to 129 females, were aggregated with wild-type E2.5 CD1 embryos to generate chimeras that were identified by the presence of both the 129 and CD1 coat and/or eye color. One female chimera was obtained that had $5 \%$ of her coat color derived from Xist-deficient cells. This female was normal, healthy, and fertile. Of 25 pups born to the female, 11 were derived from 129 cells and included 3 Xist-deficient males (see Fig. 6, lane 2) and two Xist-deficient females (Fig. 6, lanes 3,4), all of which were healthy and normal. The Xist-deficient males sired normal male offspring and mutant female offspring that exhibited the same lethal phenotype as the mutant offspring obtained from the male chimeras (data not shown). We therefore conclude that Xist-deficient cells do not require wild-type cells to undergo spermatogenesis.

To determine the $\mathrm{X}$ inactivation status of the females with a maternally inherited Xist mutation, cultured fibroblasts were obtained from 2-week-old females that harbor the mutation on the maternal $\mathrm{X}$ chromosome, and RNA FISH was used to determine the $\mathrm{X}$ inactivation pattern in these cells. Xist was expressed from the wildtype paternal X chromosome, and Pgk-1 was expressed only from the mutant $\mathrm{X}$ chromosome in all fibroblasts examined (Fig. 5G), indicating that the mutant maternal $\mathrm{X}$ chromosome was active and the paternal $\mathrm{X}$ inactive in all cells. Females that inherit the mutant $X i s t$ allele from their mothers are therefore genetically balanced. We conclude that lethality in mutant females is a consequence of paternal, but not maternal, inheritance of the mutant allele.

\section{XO females with a paternally inherited Xist mutation are healthy}

It was observed that paternal inheritance of a mutant Xist allele is lethal to females, possibly because of dosage imbalance in their imprinted tissues. This raised the possibility that lethality was contingent on the presence of a second $\mathrm{X}$ chromosome in addition to the mutant $\mathrm{X}$. To test this hypothesis, we generated females carrying a single mutant, but no wild-type, X chromosome. For this, the chimeric males described in Table 1 were mated to an XO female (see table 1). A subset of the oocytes generated by an XO female are missing an X chromosome but can nevertheless be fertilized and give rise to healthy XO females. The cross yielded two female offspring that were determined to carry the Xist mutation by PCR amplification of the neo sequence (data not shown). DNA blot hybridization (similar to Fig. 1B) revealed that both females were missing a maternally inherited wild-type $\mathrm{X}$ chromosome indicating that the

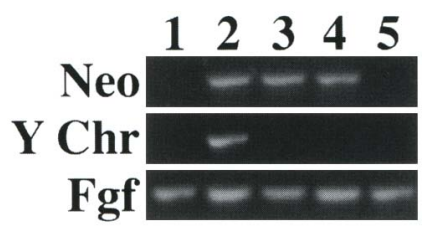

Figure 6. Genotype of a litter born to a female chimera derived from aggregation of Xist-deficient and normal embryos. PCR amplification from genomic DNA isolated from agouti pups born to the female aggregation chimera. The chimera was obtained by aggregating a Xist-deficient female E2.5 embryo, obtained from the mating of one Xist-deficient male chimera to a 129 female, with one female wild-type E2.5 CD1 embryo. DNA from individuals was amplified by PCR using primers that recognize the neo (top), Zfy (middle), and Fgf (bottom) genes. Products were electrophoresed on an agarose gel. Amplification of $\mathrm{Fg} f$ was performed as a positive control for template DNA. 
Xist-deficient females were $\mathrm{XO}$ (data not shown). Because both Xist-deficient XO females were healthy, we conclude that an XO mouse can tolerate a paternally inherited Xist mutation with no apparent ill effect.

\section{Discussion}

To investigate the role of the Xist gene in vivo, we have generated animals with a partial deletion of the encoded RNA. The phenotype of the mutant animals indicates that the Xist transcript is required for $\mathrm{X}$ chromosome inactivation. Furthermore, our results show that embryonic lethality of mutant embryos was strictly determined by the parental origin of the mutation and required the presence of more than one $\mathrm{X}$ chromosome.

\section{Role of Xist $R N A$ in $X$ chromosome inactivation}

We show that a truncated Xist gene with an intact promoter is incapable of imprinted $\mathrm{X}$ inactivation, thus providing functional evidence that the transcript derived from the Xist gene is required for gene silencing. Xist RNA may be an essential component of the heterochromatin of the inactive $\mathrm{X}$ chromosome as FISH studies revealed that the Xist RNA specifically colocalizes with the inactive X chromosome (Brown et al. 1992; Clemson et al. 1996; Panning and Jaenisch 1996). Imprinted genes encoding untranslated RNAs have also been identified on autosomes. One of these, the H19 gene, has been shown to be required in cis for the silencing of two oppositely imprinted autosomal genes, Igf-2 and Ins-2 (Leighton et al. 1995). It remains to be determined whether the RNA gene product of $H 19$ is similarly required for gene silencing. The role of a cis-acting RNA in gene silencing raises the interesting issues of how the RNA recognizes only the chromosome from which it is expressed and how this recognition leads to chromosome-wide gene inactivation.

Our finding that both $\mathrm{X}$ chromosomes are expressed in trophoblast with a paternally inherited Xist mutation indicates that Xist RNA acts downstream of the imprint that controls inactivation in extraembryonic tissues. In vitro studies have shown that Xist also functions downstream of the random selection mechanism that controls $\mathrm{X}$ inactivation in somatic cells (Penny et al. 1996). However, Xist transcription is up-regulated prior to the $\mathrm{X}$ chromosome adopting the properties of heterochromatin (Kay et al. 1993) such as late replication (Takagi 1974; Takagi et al. 1978; Sugawara et al. 1985) and gene silencing (Monk and Kathuria 1977; Epstein et al. 1978; Kratzer and Gartler 1978; Monk and Harper 1978). The production of Xist RNA, therefore, represents the earliest known step in heterochromatin formation.

\section{Death by imprinting}

Female mice inheriting the mutation from their fathers died early in embryogenesis with genetically unbalanced cells in the (extraembryonic) trophoblast but not in the mutant embryo proper (Table 2), suggesting that the le- thality was attributable to an extraembryonic defect caused by a failure to undergo imprinted inactivation. Lethality as a result of failed imprinted inactivation predicts that a mutation in the maternal $X$ chromosome, which is active and does not express Xist in extraembryonic tissues (Takagi and Sasaki 1975), should not be deleterious. This prediction was found to be true as females carrying a mutation on the maternal $\mathrm{X}$ chromosomes were normal (Table 2). A second prediction, which was also found to be true, is that the requirement of an intact $X i s t$ allele on the paternal $\mathrm{X}$ chromosome is contingent on the presence of a second $X$ chromosome (Table 2). A paternally inherited Xist gene is also not required if the entire paternal $\mathrm{X}$ chromosome is missing: XO mice with only a maternal $\mathrm{X}$ chromosome are normal (Tada et al. 1993). The lethal phenotype caused by a paternally inherited Xist mutation in XX mice is therefore entirely a result of inappropriate gene expression from the normally inactive paternal X chromosome. As extraembryonic tissues supply the embryo with nutrients and growth factors, the mutant phenotype is likely caused by a defect in this function. It has been hypothesized that imprinting leads to preimplantation repression of genes near the $\mathrm{X}$ inactivation center, which may be detrimental to androgenones and XO females with a paternally inherited X (Latham 1996). Our results are consistent with this hypothesis.

Gene expression from two X chromosomes may also contribute to the lethality of parthenogenotes and females carrying a second maternally inherited $\mathrm{X}$ chromosomal segment on a translocation chromosome. Overexpression would occur if both maternal X chromosomes carried an imprint that renders the chromosome resistant to inactivation. However, the extraembryonic tissues of these mutants revealed either wild-type (Rastan et al. 1980) or nearly wild-type (Endo and Takagi 1981; Shao and Takagi 1990; Tada and Takagi 1992) levels of X inactivation. This suggests that the lethal phenotype of these mutants may be primarily caused by the autoso-

Table 2. $X$ inactivation in Xist-deficient mice

\begin{tabular}{lllc}
\hline & & \multicolumn{2}{c}{$\begin{array}{c}\text { Number of active } \\
\text { X chromosomes }\end{array}$} \\
\cline { 3 - 4 } Genotype & Phenotype & $\begin{array}{c}\text { embryo } \\
\text { proper }\end{array}$ & $\begin{array}{c}\text { extraembryonic } \\
\text { tissue }\end{array}$ \\
\hline $\mathrm{X}_{\mathrm{m}} / \mathrm{X}_{\mathrm{p}}$ & normal & 1 & 1 \\
$\mathrm{X}_{\mathrm{m}} / \mathrm{X}_{\mathrm{p}}^{\text {Xist }}{ }^{-}$ & lethal & $1(50 \%)$ & 2 \\
$\mathrm{X}_{\mathrm{p}}^{\text {Xist }^{-}} / \mathrm{O}$ & normal & $2(50 \%)^{\mathrm{a}}$ & 1 \\
$\mathrm{X}_{\mathrm{m}}^{\text {Xist }} / \mathrm{X}_{\mathrm{p}}$ & normal & $1(50 \%)$ & 1 \\
$\mathrm{X}_{\mathrm{m} / \mathrm{y}^{-}} / \mathrm{Y}$ & normal & $2(50 \%)^{\mathrm{a}}$ & 1 \\
$\mathrm{X}_{\mathrm{m}}^{\text {Xist }} / \mathrm{Y}$ & normal & 1 & 1 \\
\hline Parental & 1 & 1 \\
\hline
\end{tabular}

Parental origin of the Xist mutation is correlated with the phenotype of the animals and the X-chromosome inactivation in the embryonic and extraembryonic tissue.

${ }^{\text {a Inferred. }}$ 
mal abnormalities that are also present. XX and XO parthenogenetic embryos display a comparable phenotype (Mann and Lovell-Badge 1987, 1988) that is less severe than that caused by a paternally inherited Xist mutation. The presence of two maternal X chromosomes is deleterious, however, because the frequency of implantation is lower for XX parthenogenetic embryos than for XO parthenogenotes (Mann and Lovell-Badge 1988). It is possible that the maternal $\mathrm{X}$ chromosomes of parthenogenotes retain a partially imprinted resistance to inactivation which, although deleterious, is difficult to detect cytologically because the unbalanced cells are rapidly selected against.

The somatic cells of both normal and growth-retarded $X i s t$-deficient embryos were balanced with an inactive wild-type $\mathrm{X}$ chromosome in every cell. Because Xist function is downstream of the random selection mechanism (Penny et al. 1996), probably both balanced and unbalanced cells were generated at the time of inactivation and the unbalanced cells were subsequently lost from the population. Such a conclusion is highly plausible as it has been shown that embryos inheriting Searle's X-autosome translocation from their mothers display a random inactivation pattern at E7 and subsequently lose all cells with an inactive chimeric chromosome (McMahon and Monk 1983) without detriment to the embryo (Lyon et al. 1964; Ohno and Lyon 1965; Disteche et al. 1981). Loss of cells with one inactivation product has also been proposed to be the source of the nonrandom inactivation pattern seen in some human patients heterozygous for X-autosome translocations (Therman and Patau 1974; Laurent et al. 1975; Leisti et al. 1975; Hagemeijer et al. 1977).

\section{$X$ inactivation and spermatogenesis}

$\mathrm{X}$ inactivation appears also to occur during spermatogenesis. During male meiosis, the $\mathrm{X}$ chromosome is heteropyknotic and transcriptionally inactive as assessed by the absence of detectable tritiated uridine incorporation (Henderson 1965; Kofman-Alfaro and Chandley 1970; Odartchenko and Pavillard 1970). It has been proposed that an inactive chromatin conformation shields the sex chromosomes from double-strand breaks that occur on autosomes, apparently as a prerequisite for synaptonemal complex formation and proper disjunction (Padmore et al. 1991; Handel and Hunt 1992). Such breaks would leave the $\mathrm{X}$ chromosome in fragments, as it can only be repaired by heteroduplex formation with a homologous chromosome. The demonstration that Xist transcript is present in testes (Borsani et al. 1991; McCarrey and Dilworth 1992; Richler et al. 1992; Salido et al. 1992) but nowhere else in the male has led to the suggestion that male $\mathrm{X}$ inactivation may be mechanistically related to female $X$ inactivation.

The observation that Xist-deficient males are fully fertile raises two possibilities that are not necessarily mutually exclusive. The first possibility is that spermatogenesis does not require $\mathrm{X}$ inactivation. The assumption that $\mathrm{X}$ inactivation is necessary for spermatogenesis is based primarily on the observation that males bearing $\mathrm{X}$-autosome translocations are sterile (Lifschytz and Lindsley 1972). It remains to be determined whether this sterility is attributable to a failure to undergo $\mathrm{X}$ inactivation. The second possibility is that $\mathrm{X}$ inactivation in males and females occurs by different mechanisms. During male meiosis both the $\mathrm{X}$ and the $\mathrm{Y}$ chromosomes reside in a distinct structure called the sex vesicle, which does not resemble a Barr body (Solari 1974). Although only the X-chromosomal sequence bearing the Xic is inactivated in females with $\mathrm{X}$-autosome translocations, both X-chromosomal portions of X-autosome translocations have been reported to reside in the sex vesicle in males (Handel and Hunt 1992). Xist transcripts are about three orders of magnitude less abundant in testes than in female cells (Kay et al. 1993). A low level of Xist expression is also seen in male and female ES cell lines that have only active X chromosomes (Beard et al., 1995; Lee et al. 1996; Panning and Jaenisch 1996). In both ES cells and in testes Xist transcripts may reflect spurious expression with no functional significance as has been proposed for other genes expressed at low levels during spermatogenesis (Willison and Ashworth 1987).

Mammalian $\mathrm{X}$ inactivation presents a number of fascinating, and still unresolved, issues. Nothing is known of the developmental signal that triggers the inactivation process nor have the targets of this signal been identified. The imprinted and random selection mechanisms that determine which chromosome is inactivated are also a mystery. However, recent experiments have functionally implicated DNA methyltransferase (Panning and Jaenisch 1996) and the Xist transcript in X-chromosome inactivation. A role for the Xist RNA in heterochromatin formation raises two additional questions. How does the Xist RNA recognize only the chromosome from which it is expressed, and how does this recognition lead to transcriptional silencing? The identification of domains within the Xist transcript and proteins that interact with Xist sequences may provide insights into these puzzling events.

\section{Materials and methods}

Construction of targeting vectors, generation of germ-line chimeras, and DNA blot analysis

Xist genomic sequence was isolated from a library of strain 129 mouse DNA. The targeting vector pXist 1 Neo was constructed by ligating a $4.8-\mathrm{kb} X b a \mathrm{I}-X h \mathrm{I}$ Xist fragment containing 912 bp of exon 1 and Xist $5^{\prime}$ upstream sequence, derived from the cloned genomic DNA, to the large $X b a I-X h o l$ fragment of pPGKRN to produce plasmid pPGKRN+4.8. pPGKRN+4.8 was cleaved with $B g I I I$ and ligated to a $5.0-\mathrm{kb} B g I I I-B g I I I$ fragment that contains the first 4418 bp of exon 6 and a portion of the intron proximal to exon 6 to produce pXist1Neo.

The J1 ES cell line was grown on embryonic fibroblast feeder cells as described previously (Li et al. 1992). Cells were electroporated with $30 \mu \mathrm{g} / \mathrm{ml}$ of targeting vector cleaved with $\mathrm{XbaI}$ (Bio-Rad gene pulser at settings of $800 \mathrm{~V}$ and $25 \mathrm{mF}$ ) and selected in $0.4 \mathrm{mg} / \mathrm{ml}$ of G418. Resistant colonies were trypsinized individually and expanded for freezing and genotyping. Genomic DNA was prepared and cleaved with $N$ coI. Blots were hybrid- 
ized to a probe derived from a $3.2-\mathrm{kb}$ BgIII-SacI fragment that contains $257 \mathrm{bp}$ of exon 6 and $\sim 3 \mathrm{~kb}$ of sequence distal to exon 6 . Selected ES clones were analyzed further by digestion with HindIII. Blots were hybridized to a probe derived from a $4.7-\mathrm{kb}$ $\mathrm{XbaI}-\mathrm{SacII}$ fragment containing Xist promoter sequence. Wildtype and targeted cells produced $8.2-$ and $5.8 \mathrm{~kb}$ bands, respectively. The membrane was rehybridized to a probe derived from a 4.0-kb XbaI-AflII exon 1 fragment to verify that this sequence was deleted in targeted cells. The targeted ES clone was injected into BALB/c blastocysts, and chimeric mice were generated as described previously (Li et al. 1992). Chimeric males were bred to BALB $/ \mathrm{c}$ females and $\mathrm{F}_{1}$ pups descended from cultured cells were identified by dark eyes and agouti coat color. Aggregation chimeras were obtained from 129 and CD1 E2.5 embryos as described (Hogan et al. 1994). The chimeric female was bred to a BALB $/ \mathrm{c}$ male, and $\mathrm{F}_{1}$ pups descended from cultured cells were identified by coat and eye color.

\section{Isolation of embryos, preparation of DNA, and PCR reactions}

Embryos were dissected from the uterus as described (Hogan et al. 1994). Color micrographs were taken with a Zeiss DS dissecting microscope, a Zeiss M35 camera, and Kodak Ektachrome Elite $200 \mathrm{film}$. Trophoblast and embryos were frozen in liquid nitrogen and stored at $-80^{\circ} \mathrm{C}$ for subsequent enzymological analysis. DNA was isolated from embryos and ES cells as described (Beard et al. 1995). The PCR primers used to detect the neo gene amplify a 477-bp sequence and are neol (5'-ATTGAACAAGATGGATTGCAC-3') and neo2 (5'-TTCGTCCAGATCATCCTGATCGAC-3'). Primers D7Mit46-F (5'-AATAGAACTTAATTGGCACAAGCC-3') and D7Mit46-R (5'-CAATTATGTGGGTGTGCATAC-3') amplify a 184-bp fragment from the 129 Igf2 locus and slightly larger PCR products from BALB/c DNA (C. Beard and M. Klemm, unpubl.). D7Mit46-F was end-labeled with $\gamma^{-}{ }^{32} \mathrm{P}$ using T4 polynucleotide kinase prior to PCR amplification. Primers used to detect the Zfy gene amplify a 618-bp fragment and are Zfyl $\left(5^{\prime}\right.$-GATAAGCTTACATAATCACATGGA-3') and Zfy2 (5'-CCTATGAAATCCTTTGCTGC-3'). PCR reaction conditions were as described previously (Beard et al. 1995). Primers used to detect exon 3 of the mouse Fgf5 gene amplify a 310 -bp product and are Fgf-f (5'-CGGATGACTGTAAGTTCAGG-3') and Fgf-r $\left(5^{\prime}\right.$-TCAGTCTGTACTTCACTGGG-5') (Beard et al. 1995).

\section{Immunohistology, derivation of cultured fibroblasts, and FISH}

Immunohistological methods were essentially as described (Lin et al. 1994). Postimplantation embryos were collected in decidua, fixed overnight in $10 \%$ buffered formalin, dehydrated in graded alcohols and xylenes, and embedded in paraffin. Sections of $5 \mu \mathrm{m}$ thickness were immunostained using anti-Pem antisera (Lin et al. 1994) with a biotinylated goat anti-rabbit antibodybased detection system (Vector Labs) using the peroxidase chromogen and diaminobenzidine (Sigma) as color substrate. Sections were counterstained with Harris' hematoxylin. Color micrographs were taken with an Olympus $\mathrm{BH}-2$ microscope, an Olympus C-35AD-2 camera with an exposure control unit, and Kodak Ektachrome 64T film. FISH was carried using probes and protocols described previously (Panning and Jaenisch 1996).

Cultured fibroblasts were obtained as described by P. Soloway (pers. comm.). One-third of an ear of a 2-week-old mouse heterozygous for a maternally inherited Xist mutation was soaked for $1 \mathrm{~min}$ in Wescodyne (West Chemical Products, Inc.) diluted 1:190 in water, rinsed four times in HEPES-buffered saline, and peeled apart along its length. Each half was placed dermis side down in a well of a gelatinized six-well tissue culture plate, covered with a sterile glass coverslip, and cultured in fibroblast media for 1 week. The skin was removed and adherent fibroblasts were passaged using standard procedures.

\section{Enzyme assays}

The enzymes Hprt and Aprt (adenine phosphoribosyl transferase) were assayed simultaneously essentially as described (Monk 1987). Samples of embryonic and extraembryonic tissue were thawed individually in $15 \mu \mathrm{l}$ of PBl.PVP (Monk 1987), fragmented by pipetting up and down, and centrifuged at 2000 rpm for $5 \mathrm{~min}$ at $4^{\circ} \mathrm{C}$. Five-microliter aliquots of supernatant were incubated for $40 \mathrm{~min}$ in $55-\mu 1$ reaction mixtures that have been described previously (Monk 1987) and included [U- $\left.{ }^{14} \mathrm{C}\right] \mathrm{ad}-$ enine (Amersham CFA.436) and/or [ ${ }^{3}$ hypoxanthine (Amersham TRA.74; NEN NET-177). Reactions were stopped, and the reaction products precipitated in $0.1 \mathrm{M}$ lanthanum chloride $\left(\mathrm{LaCl}_{3} \cdot 7 \mathrm{H}_{2} \mathrm{O}\right.$, Sigma) containing $1 \mathrm{~mm}$ unlabeled hypoxanthine (Sigma) and $1 \mathrm{~mm}$ unlabeled adenine (Sigma). Reaction products were recovered by filtration on glass fiber filters (Whatman, GF/Cl, washed with water, and counted in Biofluor emulsifier cocktail (Packard) using a Beckman LS7800 Liquid Scintillation System. The values presented in Figure 4 are the average Hprt values [corrected for spillover (Monk 1987)] divided by the Aprt values (also corrected). Aprt is an autosomal gene.

\section{Acknowledgments}

We thank Tzu-Ping Lin and Carol MacLeod for donating antiPem antisera and offering helpful technical advice. We also thank Jeanne Reis and Ruth Curry for excellent technical assistance; Anne Vassalli, Caroline Beard, and the other members of the laboratory for advice and helpful discussions; and Laura Gammill and Peggy Kolm for critical reading of the manuscript. This work was supported by a grant from the National Institutes of Health/National Cancer Institute (R35-CA44339) to R.J. B.P. is supported by a Medical Research Council of Canada Postdoctoral Fellowship. Y.M. is supported by the Cancer Research Fund of the Damon Runyon-Walter Winchell Foundation Fellowship, DRG-1292.

The publication costs of this article were defrayed in part by payment of page charges. This article must therefore be hereby marked "advertisement" in accordance with 18 USC section 1734 solely to indicate this fact.

\section{References}

Barr, M.L. 1959. Sex chromatin and phenotype in man. Science 130: 679-685.

Beard, C., E. Li, and R. Jaenisch. 1995. Loss of methylation activates Xist in somatic but not in embryonic cells. Genes \& Dev. 9: 2325-2334.

Beutler, E., M. Yeh, and V.F. Fairbanks. 1962. The normal human female as a mosaic of X-chromosome activity: Studies using the gene for G-6-PD-deficiency as a marker. Proc. Natl. Acad. Sci. 48: 9-16.

Borsani, G., R. Tonlorenzi, M.C. Simmler, L. Dandolo, D. Arnaud, V. Capra, M. Grompe, A. Pizzuti, D. Muzny, et al. 1991. Characterization of a murine gene expressed from the inactive X chromosome. Nature 351: 325-328.

Brockdorff, N., A. Ashworth, G.F. Kay, P. Cooper, S. Smith, V.M. McCabe, D.P. Norris, G.D. Penny, D. Patel, et al. 1991. Conservation of position and exclusive expression of mouse Xist from the inactive X chromosome. Nature 351: 329-331. 
Brockdorff, N., A. Ashworth, G.F. Kay, V.M. McCabe, D.P. Norris, P.J. Cooper, S. Swift, and S. Rastan. 1992. The product of the mouse Xist gene is a $15 \mathrm{~kb}$ inactive $\mathrm{X}$-specific transcript containing no conserved ORF and located in the nucleus. Cell 71: 515-526.

Brown, C.J., A. Ballabio, J.L. Rupert, R.G. Lafreniere, M. Grompe, R. Tonlorenzi, and H.F. Willard. 1991. A gene from the region of the human $\mathrm{X}$ inactivation centre is expressed exclusively from the inactive $\mathrm{X}$ chromosome. Nature 349: 38-44.

Brown, C.J., B.D. Hendrich, J.L. Rupert, R.G. Lafreniere, Y. Xing, J. Lawrence, and H.F. Willard. 1992. The human XIST gene: Analysis of a $17 \mathrm{~kb}$ inactive X-specific RNA that contains conserved repeats and is highly localized within the nucleus. Cell 71: 527-542.

Clemson, C.M., J.A. McNeil, H.F. Willard, and J.B. Lawrence. 1996. XIST RNA paints the inactive X chromosome at interphase: Evidence for a novel RNA involved in nuclear/ chromosome structure. J. Cell Biol. 132: 259-275.

Disteche, C.M., E.M. Eicher, and S.A. Latt. 1981. Late replication patterns in adult and embryonic mice carrying Searle's X-autosome translocation. Exp. Cell Res. 133: 357-362.

Eicher, E.M. 1970. X-autosome translocations in the mouse: Total inactivation versus partial inactivation of the $\mathrm{X}$ chromosome. Adv. Genet. 15: 175-259.

Endo, S. and N. Takagi. 1981. A prelininary cytogenetic study of $\mathrm{X}$ chromosome inactivation in diploid parthenogenetic embryos from LT/Sv mice. Ipn. J. Genet. 56: 349-356.

Epstein, C.J., S. Smith, B. Travis, and G. Tucker. 1978. Both X chromosomes function before visible $\mathrm{X}$ chromosome activation in female mouse embryos. Nature 274: 500-502.

Gardner, H., J. Kreidberg, V. Koteliansky, and R. Jaenisch. 1996. Deletion of integrin $\alpha 1$ by homologous recombination permits normal murine development but gives rise to a specific defect in cell adhesion. Dev. Biol. 175: 301-313.

Hagemeijer, J., E.M. Hoovers, E. Smit, and D. Bootsma. 1977. Replication pattern of the X-chromosome in three X-autosomal translocations. Cytogenet. Cell. Genet. 18: 333-348.

Handel, M.A. and P.A. Hunt. 1992. Sex-chromosome pairing and activity during mammalian meiosis. BioEssays 14: 817822 .

Henderson, S.A. 1965. RNA synthesis during male meiosis and spermatogenesis. Chromosoma 15: 345-366.

Hogan, B., R. Beddington, F. Costantini, and E. Lacy. 1994. Manipulating the mouse embryo: A laboratory manual. Cold Spring Harbor Laboratory Press, Cold Spring Harbor, NY.

Hooper, M.L., K. Hardy, A. Handyside, S. Hunter, and M. Monk. 1987. HPRT-deficient (Lesch-Nyhan) mouse embryos derived from germline colonization by cultured cells. Nature 326: 292-295.

Jeppesen, P. and B.M. Turner. 1993. The inactive X chromosome in female mammals is distinguished by a lack of histone $\mathrm{H} 4$ acetylation, a cytogenetic marker for gene expression. Cell 74: 281-289.

Kay, G.F., G.D. Penny, D. Patel, A. Ashworth, N. Brockdorff, and S. Rastan. 1993. Expression of Xist during mouse development suggests a role in the initiation of $\mathrm{X}$ chromosome inactivation. Cell 72: 171-182.

Kofman-Alfaro, S. and A.C. Chandley. 1970. Meiosis in the male mouse. An autoradiographic investigation. Chromosoma 31: 404-420.

Kratzer, P.G. and S.M. Gartler. 1978. HGPRT activity changes in pre-implantation mouse embryos. Nature 274: 503-504.

Latham, K.E. 1996. X chromosome imprinting and inactivation in the early mammalian embryo. Trends Genet. 12: 134 138.
Laurent, C., M.-C. Biemont and B. Dutrillaux. 1975. Sur quatre noveaux cas de translocation du chromosome $\mathrm{X}$ chez 1'homme. Humangenetik 26: 35-46.

Lee, J.T., W.M. Strauss, J.A. Dausman, and R. Jaenisch. 1996. A $450 \mathrm{~kb}$ transgene displays properties of the mammalian $\mathrm{X}$ inactivation center. Cell 86: 83-94.

Leighton, P.A., R.S. Ingram, J. Eggenschwiler, A. Efstratiadis, and S.M. Tilghman. 1995. Disruption of imprinting caused by deletion of the $H 19$ gene region in mice. Nature 375: $34-$ 39.

Leisti, J.T., M.M. Kaback, and D.L. Rimoin. 1975. Human Xautosome translocations: Differential inactivation of the $\mathrm{X}$ chromosome in a kindred with an X-9 translocation. Am. $J$. Hum. Genet. 27: 441-453.

Li, E., T.H. Bestor, and R. Jaenisch. 1992. Targeted mutation of the DNA methyltransferase gene results in embryonic lethality. Cell 69: 915-926.

Li, E., C. Beard, and R. Jaenisch. 1993. Role for DNA methylation in genomic imprinting. Nature 366: 362-365.

Lifschytz, E. and D.L. Lindsley. 1972. The role of X-chromosome inactivation during spermatogenesis. Proc. Nat. Acad. Sci. 69: 182-186.

Lin, T.-P., P.A. Labosky, L.B. Grabel, C.A. Kozak, J.L. Pitman, J. Kleeman, and C.L. MacLeod. 1994. The Pem homeobox gene is X-linked and exclusively expressed in extraembryonic tissues during early murine development. Dev. Biol. 166: 170179.

Lyon, M.F. 1961. Gene action in the X-chromosome of the mouse (Mus musculus L). Nature 190: 372-373.

. 1972. X-chromosome inactivation and development patterns in mammals. Biol. Rev. 47: 1-35.

Lyon, M.F., A.G. Searle, C.E. Ford, and S. Ohno. 1964. A mouse translocation suppressing sex-linked variegation. Cytogenetics 3: 306-323.

Mann, J.R. and R.H. Lovell-Badge. 1987. The development of XO gynogenetic mouse embryos. Development 99: 411-416.

- 1988. Two maternally derived X chromosomes contribute to parthenogenetic inviability. Development 104: 129136.

McCarrey, J.R. and D.D. Dilworth. 1992. Expression of Xist in mouse germ cells correlates with X-chromosome inactivation. Nature Genet. 2: 200-203.

McMahon, A. and M. Monk. 1983. X-chromosome activity in female mouse embryos heterozygous for Pgk-1 and Searle's translocation, $\mathrm{T}\left(\mathrm{X}_{j} 16\right)$ 16H. Genet. Res. Camb. 41: 69-83.

Monesi, V. 1965. Differential rate of ribonucleic acid synthesis in the autosomes and sex chromosomes during male meiosis in the mouse. Chromosoma 17: 11-21.

Monk, M. 1987. Biochemical microassays for X-chromosomelinked enzymes HPRT and PGK. In Mammalian development: A practical approach (ed. M. Monk), pp. 139-161. IRL Press, Oxford, UK.

Monk, M. and M.I. Harper. 1978. X chromosome activity in pre-implantation embryos from XX and XO mothers. I. Embryol. Exp. Morphol. 46: 53-64.

Monk, M. and H. Kathuria. 1977. Dosage compensation for an $\mathrm{X}$-linked gene in pre-implantation mouse embryos. Nature 270: 599-601.

Moore, T.F. and D.G. Whittingham. 1992. Imprinting of phosphoribosyltransferases during preimplantation development of the mouse mutant, Hprtb-m3. Development 115: 10111016.

Odartchenko, N. and M. Pavillard. 1970. Late DNA replication in male mouse meiotic chromosomes. Science 167: 11331134.

Ohno, S. and T.S. Hauschka. 1960. Allocycly of the X-chromo- 
some in tumors and normal tissues. Cancer Res. 20: 541545.

Ohno, S. and M.F. Lyon. 1965. Cytological study of Searle's $\mathrm{X}$-autosome translocation in Mus musculus. Chromosoma 16: $90-100$.

Padmore, R., L. Cao, and N. Kleckner. 1991. Temporal comparison of recombination and synaptonemal complex formation during meiosis in S. cerevisiae. Cell 66: 1239-1256.

Panning, B. and R. Jaenisch. 1996. DNA hypomethylation can activate Xist expression and silence X-linked genes. Genes \& Dev. 10: 1991-2002.

Penny, G.D., G.F. Kay, S.A. Sheardown, S. Rastan, and N. Brockdorff. 1996. Requirement for Xist in X chromosome inactivation. Nature 379: 131-137.

Pfeifer, K. and S.M. Tilghman. 1994. Allele-specific gene expression in mammals: The curious case of the imprinted RNAs. Genes \& Dev. 8: 1867-1874.

Rastan, S. 1983. Non-random X-chromosome inactivation in mouse X-autosome translocation embryos-location of the inactivation centre. J. Embryol. Exp. Morphol. 78: 1-22.

Rastan, S. and S.D.M. Brown. 1990. The search for the mouse X-chromosome inactivation centre. Genet. Res. Camb. 56: 99-106.

Rastan, S., M.H. Kaufman, A.H. Handyside, and M.F. Lyon. 1980. X-chromosome inactivation in extraembryonic membranes of diploid parthenogenetic mouse embryos demonstrated by differential staining. Nature 288: 172-173.

Richler, C., H. Soreq, and J. Wahrman. 1992. X inactivation in mammalian testis is correlated with inactive $\mathrm{X}$-specific transcription. Nature Genet. 2: 192-195.

Russell, L.B. 1961. Genetics of mammalian sex chromosomes. Science 133: 1795-1803.

- 1963. Mammalian X-chromosome action: Inaction limited in spread and in region of origin. Science 140: 976-978.

Salido, E.C., P.H. Yen, T.K. Mohandas, and L.J. Shapiro. 1992. Expression of the $\mathrm{X}$ inactivation-associated gene XIST during spermatogenesis. Nature Genet. 2: 196-199.

Shao, C. and N. Takagi. 1990. An extra maternally derived X chromosome is deleterious to early mouse development. $D e$ velopment 110: 969-975.

Solari, A.J. 1974. The behavior of the XY pair in mammals. Int. Rev. Cytol. 38: 273-317.

Spindle, A., K.S. Sturm, M. Flannery, J.J. Meneses, K. Wu, and R.A. Pedersen. 1996. Defective chorioallantoic fusion in mid-gestation lethality of parthenogenone-tetraploid chimeras. Dev. Biol. 173: 447-458.

Sugawara, O., N. Takagi, and M. Susaki. 1985. Correlation between $\mathrm{X}$ chromosome inactivation and cell differentiation in female pre-implantation mouse embryos. Cytogenet. Cell. Genet. 39: 210-219.

Tada, T. and N. Takagi. 1992. Early development and X-chromosome inactivation in mouse parthenogenetic embryos. Mol. Reprod. Dev. 31: 20-27.

Tada, T., N. Tagaki, and I.-D. Adler. 1993. Parental imprinting on the mouse X chromosome: Effects on the early development of XO, XXY, and XXX embryos. Genet. Res. Camb. 62: 139-148.

Takagi, N. 1974. Differentiation of the X chromosomes in early female mouse embryos. Exp. Cell Res. 86: 127-135.

Takagi, N. and M. Sasaki. 1975. Preferential inactivation of the paternally derived $\mathrm{X}$ chromosome in the extraembryonic membranes of the mouse. Nature 256: 640-642.

Takagi, N., N. Wake, and M. Sasaki. 1978. Cytologic evidence for preferential inactivation of the paternally derived $\mathrm{X}$ chromosome in XX mouse blastocysts. Cytogenet. Cell Genet. 20: $240-248$.
Therman, E. and K. Pätau. 1974. Abnormal X-chromosomes in man: Origin, behaviour and effects. Humangenetik 25: 1-16.

Willison, K.W. and A. Ashworth. 1987. Spermatogenic gene expression. Trends Genet. 3: 351-355.

Zemel, S., M.S. Bartolomei, and S.M. Tilghman. 1992. Physical linkage of two mammalian imprinted genes. Nature Genet. 2: 61-65. 


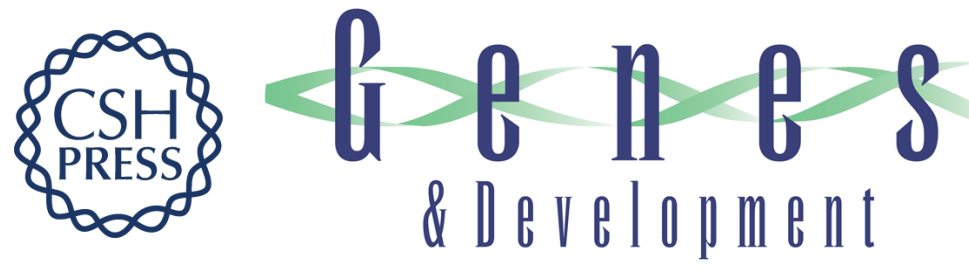

\section{Xist-deficient mice are defective in dosage compensation but not spermatogenesis.}

Y Marahrens, B Panning, J Dausman, et al.

Genes Dev. 1997, 11:

Access the most recent version at doi:10.1101/gad.11.2.156

References This article cites 68 articles, 15 of which can be accessed free at: http://genesdev.cshlp.org/content/11/2/156.full.html\#ref-list-1

License

Email Alerting

Service

Receive free email alerts when new articles cite this article - sign up in the box at the top right corner of the article or click here.

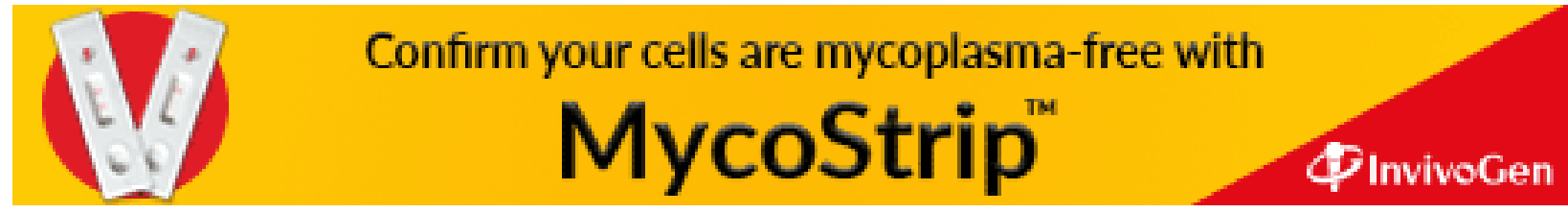

